\title{
Cardiac telerehabilitation as an alternative to centre-based cardiac rehabilitation
}

\author{
R. W. M. Brouwers · H. J. van Exel · J. M. C. van Hal · H. T. Jorstad · E. P. de Kluiver · R. A. Kraaijenhagen • \\ P. M. J. C. Kuijpers · M. R. van der Linde · R. F. Spee · M. Sunamura · N. H. M. K. Uszko-Lencer · T. Vromen · \\ M. E. Wittekoek - H. M. C. Kemps for the Committee for Cardiovascular Prevention and Cardiac Rehabilitation \\ of the Netherlands Society of Cardiology
}

Published online: 3 June 2020

(C) The Author(s) 2020

\begin{abstract}
Multidisciplinary cardiac rehabilitation (CR) reduces morbidity and mortality and increases quality of life in cardiac patients. However, CR utilisation rates are low, and targets for secondary prevention of cardiovascular disease are not met in the majority of patients, indicating that secondary prevention programmes such as CR leave room for improvement. Cardiac telerehabilitation (CTR) may resolve several barriers that impede CR utilisation and sustainability of its effects. In CTR, one or more modules of CR are delivered outside the environment of the hospital or CR centre, using monitoring devices and remote communication with patients. Multidisciplinary CTR is a safe and at least equally (cost-)effective alternative to centre-based CR, and is therefore recommended in a recent addendum to the Dutch multidisciplinary CR guidelines. In this article, we describe the background
\end{abstract}

\author{
R. W. M. Brouwers $(\bowtie) \cdot$ R. F. Spee · H. M. C. Kemps \\ Flow, Centre for Prevention, Telemedicine and \\ Rehabilitation in Chronic Disease, Máxima Medical Centre, \\ Eindhoven, The Netherlands \\ r.brouwers@mmc.nl \\ H. J. van Exel \\ Basalt Rehabilitation, Leiden, The Netherlands \\ J. M. C. van Hal \\ Department of Cardiology, Slingeland Hospital, \\ Doetinchem, The Netherlands
}

\section{H. T. Jorstad}

Department of Cardiology, Amsterdam University Medical

Centre, University of Amsterdam, Amsterdam, The

Netherlands

\section{E. P. de Kluiver}

Isala Heart Centre, Zwolle, The Netherlands

\section{R. A. Kraaijenhagen}

NDDO Institute for Prevention and E-health Development

(NIPED), Amsterdam, The Netherlands and core components of this addendum on CTR, and discuss its implications for clinical practice and future perspectives.

Keywords Cardiac rehabilitation · Cardiac telerehabilitation · Telemonitoring · Coronary artery disease $\cdot$ Chronic heart failure

\section{Introduction}

In December 2018, an addendum to the Dutch Multidisciplinary Guideline for Cardiac Rehabilitation concerning cardiac telerehabilitation (CTR) was published [1]. In this article, we describe the background and core components of this addendum on CTR, and discuss its implications for clinical practice and future perspectives.

P. M. J. C. Kuijpers · N. H. M. K. Uszko-Lencer · T. Vromen Department of Cardiology, Maastricht University Medical Centre, Maastricht, The Netherlands

M. R. van der Linde

Department of Cardiology, Nij Smellinghe Hospital,

Drachten, The Netherlands

R. F. Spee · H. M. C. Kemps

Department of Cardiology, Máxima Medical Centre,

Veldhoven, The Netherlands

\section{Sunamura}

Capri Cardiac Rehabilitation, Rotterdam, The Netherlands

N. H. M. K. Uszko-Lencer

Department of Research and Education, Centre of Expertise for Chronic Organ Failure (CIRO+), Horn, The Netherlands

M. E. Wittekoek

HeartLife Klinieken, Utrecht, The Netherlands 


\section{Background}

Multidisciplinary cardiac rehabilitation (CR) reduces morbidity and mortality and increases quality of life in cardiac patients [2-4]. Outpatient CR is a comprehensive intervention, in which patients are offered an individualised centre-based programme that may consist of one or more group-based modules or therapies (i.e. exercise training, education, relaxation therapy, psycho-educative prevention [PEP] therapy, smoking cessation therapy) and/or individual treatment by a psychologist, dietician or social worker [5]. In the Netherlands, the duration of the programme is approximately 12 weeks, and its content is based on an individual assessment of physical, mental, behavioural and social risk factors [6]. Traditionally, CR programmes have mainly been developed for patients with coronary artery disease (CAD), but in the last two decades it has been demonstrated that other cardiac patients benefit from CR as well (Tab. 1; $[3,7]$ ).

Despite proven benefits and strong (class IA) guideline recommendations [8-10], less than half of eligible patients with $\mathrm{CAD}$ participate in $\mathrm{CR}$, due to both insufficient referral by medical professionals and suboptimal enrolment of patients who are referred [11, 12]. Data from the EUROASPIRE IV survey [12] suggest that in the Netherlands, $72 \%$ of patients with an acute coronary syndrome and/or coronary revascularisation were referred for CR, of which $83 \%$ ultimately attended a CR programme (resulting in a $60 \%$ participation rate). As participation rates in patients with chronic coronary syndromes and/or without coronary revascularisation and patients with chronic heart failure (CHF) or arrhythmias are dramatically lower (1-30\%) $[13,14]$, we may assume these patients are referred even less often. Multiple factors may contribute to low referral and enrolment rates, including physicians' and patients' attitudes towards CR and, importantly, lack of capacity at CR centres or hospitals [15].

Table 1 Indications for cardiac rehabilitation

\begin{tabular}{l} 
Indications for cardiac rehabilitation \\
Coronary artery disease \\
- Acute coronary syndromes \\
- Coronary revascularisation \\
a. PCI \\
b. CABG \\
- Chronic coronary syndromes \\
\hline Chronic heart failure (mainly HFrEF) \\
Valve surgery for valvular heart disease \\
Atrial fibrillation \\
\hline Congenital heart disease \\
Implantable cardioverter defibrillator implantation \\
\hline Heart transplantation \\
\hline PCI percutaneous coronary intervention, $C A B G$ coronary artery bypass \\
grafting, HFrEF heart failure with reduced ejection fraction
\end{tabular}

A second challenge lies in the fact that once enrolled, up to one third of participants prematurely drop out of a CR programme [12, 16]. Determinants of dropout have been evaluated mainly in patients with CAD and include higher age, lower socio-economic status and worse cardiovascular risk profiles [16-18]. Patient-related individual factors (attitudes towards heart disease or healthcare services) and contextual factors (e.g. social support, accessibility of CR programmes) may lead to discontinuation of CR and suggest that patients would benefit from individually tailored CR programmes [19], although convincing evidence on interventions that increase CR adherence is scarce [20]. Finally, besides low CR utilisation and completion rates, targets for secondary prevention of cardiovascular disease are not met in the majority of cardiac patients [21, 22], indicating that secondary prevention programmes, such as $\mathrm{CR}$, leave room for improvement.

CTR may resolve several barriers at patient level, healthcare professional level and (healthcare) system level that hamper the utilisation of CR and sustainability of its effects [15, 23]. Examples of these barriers include transport difficulties (patient level), low physician endorsement of CR (professional level) or limited facilities to provide supervised exercise training (system level). In CTR, one or more therapies of CR are delivered outside the environment of the hospital or CR centre, using monitoring devices and remote communication with patients, preferably using modern communication technology such as internet or video consultation. Individual health data (e.g. heart rate $[\mathrm{HR}]$ during exercise, daily physical activity [PA] or nutritional intake) are monitored to enable personalised feedback and education by a healthcare professional [24]. Recent systematic reviews and metaanalyses show that multidisciplinary CTR or exercisebased CTR is a safe and at least equally (cost-)effective alternative to regular, centre-based CR in patients with CAD or CHF (Tab. 2; [24-27]). CTR may also serve as a highly cost-effective addition to centre-based CR, as demonstrated by the Telerehab III trial [28]. In addition, implementation of CTR may reduce healthcare costs due to reduced absenteeism from work and reduced rehospitalisation rates [24, 29]. Therefore, CTR is considered a valuable secondary cardiovascular prevention component by the European Association of Preventive Cardiology and European Society of Cardiology [23, 30, 31].

\section{Patient selection and referral for CTR}

Based on the available scientific evidence, two CTR modules are recommended as an alternative or addition to centre-based CR, namely remotely supervised exercise training (teleFIT module) and remotely supervised PEP therapy (telePEP module). In the future, other CR modules (e.g. education, cardiovascular risk management and nutritional counselling) could also 
Table 2 Overview of systematic reviews and meta-analyses on cardiac telerehabilitation

\begin{tabular}{|c|c|c|c|c|c|}
\hline Authors & Studies & Patients & Intervention & Control group & Results \\
\hline \multirow[t]{3}{*}{$\begin{array}{l}\text { Frederix et al. } \\
\text { [24] }\end{array}$} & \multirow{3}{*}{$\begin{array}{l}37 \text { publi- } \\
\text { cations } \\
\text { (26 RCTs) }\end{array}$} & \multirow{3}{*}{$\begin{array}{l}\text { CAD } \\
\text { CHF } \\
\text { Other }^{\mathrm{a}}\end{array}$} & \multirow{3}{*}{$\begin{array}{l}\text { Multidisciplinary CTR (multiple } \\
\text { CR modules, delivered either } \\
\text { separately or combined) }\end{array}$} & $\begin{array}{l}\text { Centre-based CR } \\
\text { (10 studies) }\end{array}$ & \multirow{3}{*}{$\begin{array}{l}\downarrow \text { Adverse events and hospitalisations } \\
\uparrow \text { Adherence to physical activity guidelines } \\
\text { (as compared to control group) }\end{array}$} \\
\hline & & & & $\begin{array}{l}\text { Usual care } \\
\text { (17 studies) }\end{array}$ & \\
\hline & & & & $\begin{array}{l}\text { No control group, or none } \\
\text { described } \\
\text { (10 studies) }\end{array}$ & \\
\hline $\begin{array}{l}\text { Huang et al. } \\
\text { [26] }\end{array}$ & 9 RCTs & CAD & $\begin{array}{l}\text { Remotely supervised exercise } \\
\text { training programme }\end{array}$ & $\begin{array}{l}\text { Centre-based CR } \\
\text { (9 RCTs) }\end{array}$ & $\begin{array}{l}\text { No difference in mortality, CV risk factors, QoL } \\
\text { (as compared to centre-based CR) }\end{array}$ \\
\hline \multirow[t]{2}{*}{$\begin{array}{l}\text { Rawstorn } \\
\text { et al. [25] }\end{array}$} & \multirow[t]{2}{*}{11 RCTs } & \multirow[t]{2}{*}{ CAD } & \multirow[t]{2}{*}{$\begin{array}{l}\text { Remotely supervised exercise } \\
\text { training programme }\end{array}$} & $\begin{array}{l}\text { Centre-based CR } \\
\text { (5 RCTs); }\end{array}$ & \multirow{2}{*}{$\begin{array}{l}\uparrow \mathrm{PAL} ; \uparrow \mathrm{EA} ; \\
\downarrow \mathrm{DBP} ; \downarrow \text { LDL-C } \\
\text { (as compared to centre-based CR) }\end{array}$} \\
\hline & & & & $\begin{array}{l}\text { Usual care } \\
\text { (6 RCTs) }\end{array}$ & \\
\hline \multirow[t]{3}{*}{$\begin{array}{l}\text { Van Veen } \\
\text { et al. [27] }\end{array}$} & \multirow[t]{3}{*}{19 RCTs } & \multirow[t]{3}{*}{$\begin{array}{l}\text { CAD } \\
\text { CHF }\end{array}$} & \multirow[t]{3}{*}{$\begin{array}{l}\text { E-coaching (online } \\
\text { communication) }\end{array}$} & $\begin{array}{l}\text { Centre-based CR } \\
(1 \mathrm{RCT})\end{array}$ & \multirow[t]{3}{*}{$\begin{array}{l}\uparrow \text { Functional capacity; } \\
\uparrow \text { Psychosocial well-being }\end{array}$} \\
\hline & & & & Telephone coaching (1 RCT) & \\
\hline & & & & $\begin{array}{l}\text { Usual care } \\
\text { (17 RCTs) }\end{array}$ & \\
\hline
\end{tabular}

$R C T$ randomised controlled trial, $C A D$ coronary artery disease, $C H F$ chronic heart failure, $C R$ cardiac rehabilitation, $C T R$ cardiac telerehabilitation, $L D L-C$ lowdensity lipoprotein cholesterol, $C V$ cardiovascular, QoL quality of life, $P A L$ physical activity level, EA exercise adherence, DBP diastolic blood pressure a Other patient subgroups: after cardiac surgery, implantation of an implantable cardioverter defibrillator or with congenital heart disease. Adapted from [1]

be delivered remotely while retaining the multidisciplinary character of the intervention. The choice of either a centre-based or a remotely supervised module should depend on a patient's preference and his or her motivation to complete either module.

In recent clinical trials evaluating the effects of remotely supervised exercise training as part of CTR (or exercise-based CTR), the majority of patients had CAD (either acute or chronic coronary syndromes) with a low to moderate risk of (cardiovascular) complications [24-26, 32]. Patients with CHF were underrepresented in most exercise-based CTR trials, and only a small number of clinical trials evaluated the effects of exercise-based CTR solely in patients with CHF. Therefore, remotely supervised exercise training as part of CTR is recommended only as an alternative or addition to centre-based CR in low- to moderaterisk (i.e. non-complex) patients [33] with an indication for CR due to any form of CAD (Fig. 1).

In clinical trials evaluating the effects of remotely supervised psychological interventions or interventions to improve lifestyle behaviour, complex patients (mostly with CHF) were better represented than in exercise-based CTR trials [27]. Therefore, remotely supervised PEP therapy (see section 'TelePEP module') as part of CTR is, more broadly, recommended as an alternative to centre-based CR in low- to high-risk (i.e. both non-complex and complex) [33] patients with an indication for $\mathrm{CR}$, regardless of underlying cardiac pathology.

\section{Referral}

Patients are referred for CR by their cardiologist after an assessment of risk or the presence of contra-indications for CR. Eligibility for CTR modules is assessed similarly to centre-based CR [6], including an intake procedure, exercise test and questionnaires. We recommend that eligibility assessment and CTR modules are managed by a CR centre equipped with a multidisciplinary CR team (including a cardiologist) to ensure early and accurate communication with qualified professionals. We do not recommend that these procedures are supervised by a general practitioner-led team due to insufficient expertise regarding cardiac pathologies, cardiac pharmacology and CR. It should, however, be possible that parts of the exercise programme are executed at the practice of a certified physical therapist outside the CR centre, (remotely) supervised by a multidisciplinary CR team located at the CR centre.

\section{TeleFIT module}

\section{Content of the programme and patient selection}

The content of a remotely supervised exercise programme depends, similar to a centre-based programme, on patients' individual goals, preferences and functional capacity. It is recommended that a training or exercise modality is selected based on a patient's preference, as this increases long-term PA and exercise adherence [34]. We only recommend continuous aerobic training for remotely supervised exercise training, as safety data on remotely supervised high-intensity interval training is currently scarce $[35,36]$. Patients with myocardial ischaemia and/or ventricular arrhythmia performing low- to moderate-intensity exercise (documented during exercise testing) should be excluded from remotely supervised exercise training and be referred for centrebased CR (or clinical evaluation, as appropriate). 


\section{CARDIAC TELEREHABILITATION}

\begin{tabular}{|c|c|}
\hline Advantages & Clinical effects \\
\hline $\begin{array}{l}\text { Resolution of patient-reported } \\
\text { barriers to centre-based CR } \\
\text { participation } \\
\text { - Upscaling CR services with } \\
\text { limited facilities for exercise } \\
\text { training } \\
\text { - Self-monitoring of exercise and } \\
\text { physical activity data }\end{array}$ & $\begin{array}{l}\text { - At least equal to centre-based } \\
\text { CR in terms of safety and cost- } \\
\text { effectiveness } \\
\text { - Potential cost-savings due to } \\
\text { reduced absenteeism and } \\
\text { rehospitalisation rates } \\
\text { - Potential improvement of long- } \\
\text { term CV risk management }\end{array}$ \\
\hline
\end{tabular}

\begin{tabular}{|c|c|c|}
\hline \multicolumn{3}{|c|}{ Patient selection and programme content } \\
\hline $\begin{array}{c}\text { Module } \\
\text { pathology }\end{array}$ & TeleFIT & TelePEP \\
\hline $\begin{array}{c}\text { Risk of } \\
\text { (cardiovascular) } \\
\text { complications }\end{array}$ & Low to moderate & Any cardiac pathology \\
\hline $\begin{array}{c}\text { Programme } \\
\text { content }\end{array}$ & $\begin{array}{c}\text { Continuous aerobic } \\
\text { training in patient- } \\
\text { preferred exercise } \\
\text { modality }\end{array}$ & $\begin{array}{c}\text { Behavioural change in } \\
\text { cardiovascular lifestyle } \\
\text { and/or treatment of } \\
\text { anxiety or mood }\end{array}$ \\
\hline $\begin{array}{c}\text { Remote } \\
\text { monitoring } \\
\text { parameters }\end{array}$ & $\begin{array}{c}\text { Heart rate, physical } \\
\text { activity, subjective } \\
\text { exercise intensity, } \\
\text { complaints }\end{array}$ & $\begin{array}{c}\text { Homework assignments, } \\
\text { educational reading, } \\
\text { questionnaires }\end{array}$ \\
\hline $\begin{array}{c}\text { Supervising } \\
\text { professional }\end{array}$ & $\begin{array}{c}\text { Physical therapist or } \\
\text { exercise specialist }\end{array}$ & $\begin{array}{c}\text { Psychologist or } \\
\text { behavioural change } \\
\text { specialist }\end{array}$ \\
\hline $\begin{array}{c}\text { Mode of } \\
\text { communication }\end{array}$ & Video or telephone consultation, secure messaging \\
\hline
\end{tabular}

\begin{tabular}{|l|}
\hline \multicolumn{1}{|c|}{ Future perspectives } \\
\hline - Extending CTR interventions beyond duration of traditional CR \\
programmes (3 months) \\
- Further personalisation and tailoring of CTR interventions to reach \\
subgroups currently underrepresented in $\mathrm{C}(\mathrm{T}) \mathrm{R}$ \\
- Adaptation of CTR interventions for application in other chronic \\
diseases.
\end{tabular}

Fig. 1 Characteristics of cardiac telerehabilitation programmes. (CR cardiac rehabilitation, CV cardiovascular, CTR cardiac telerehabilitation)

Before the exercise training sessions are transferred to a patient's home environment, the patient should follow a limited number of supervised centre-based exercise sessions. In these sessions, patients' goals and preferred training or exercise modality are discussed, and it is possible to evaluate exercise-related physical or mental complaints. In addition, it is discussed how home-based exercise and PA will be monitored and how remote coaching will be executed.

\section{Remote monitoring and coaching}

A physical therapist (or other healthcare professional) specialised in exercise-based CR and trained in motivational interviewing records a patient's goals and target HR zone (as a measure for exercise intensity) in the electronic health record and/or in a CTR-specific web application. The target HR zone is based on the current Dutch Multidisciplinary Guideline for CR and the patient's individual goals [5, 37]. During homebased exercise sessions, the patient should at least monitor his HR by means of a HR monitor (chest strap and/or wrist watch). The HR during home-based exercise sessions should be visualised (e.g. in a graph) in an online web (or mobile) application, and HR data should be accessible for both the patient and the supervising healthcare professional. It is recommended that the exercise modality, subjective exercise intensity (e.g. Borg scale) and exercise-related physical or mental complaints are also recorded. Remote coaching can be executed through the online application (secured messaging) and/or telephone and/or video consultation.

Besides monitoring $\mathrm{HR}$, it is recommended that daily PA is monitored in the online application as well. Objectively measured PA is more reliable than self-reported PA, and for objective measurement of PA accelerometers (uni-, bi- or tri-axial) are preferred to pedometers, since they correlate better with energy expenditure and-in contrast to pedometers-are not designed for a specific exercise modality (e.g. walking) [38-40]. Self-monitoring of exercise and PA data increases levels of self-management and self-care, leading to a more sustainable improvement in healthcare behaviour [41-43].

\section{TelePEP module}

PEP therapy is a structured behavioural change programme, aimed at improving an individual's lifestyle in order to reduce the risk of recurrent cardiovascular events and/or cardiovascular disease progression [5]. The programme focuses mainly on behavioural change in PA, smoking, alcohol consumption, nutrition and stress, but may also address anxiety, depression, or resumption at work. In PEP, several evidencebased therapies can be used, including cognitive behavioural therapy, acceptance and commitment therapy, relaxation techniques and mindfulness.

\section{Patient selection}

Patients eligible for PEP are also eligible for telePEP. It is recommended that every patient entering CR is screened for anxiety, depression and emotional imbalance using validated questionnaires (i.e. Hospital Anxiety and Depression Scale [HADS], 7-item Generalised Anxiety Disorder Scale [GAD-7], Patient Health Questionnaire [PHQ-9], Kwaliteit van Leven bij Hartpatiënten [KVL-H] and RAND 20-Item Short Form Health Survey [RAND SF-20]) [6]. If any of these screening instruments indicate an increased risk for anxiety or depressive disorders, further assessment by a psychologist or psychiatrist is recommended. Patients with known psychopathology may participate in (tele)PEP only after consultation of a psychologist. 


\title{
Advertisement placed here.
}

\author{
ces bohn \\ CL van loghum
}

Houten 2020 


\title{
Advertisement placed here.
}

\author{
ces bohn \\ CL van loghum
}

Houten 2020 


\section{Content of the programme}

Before starting telePEP, patients have an intake appointment (face to face or through video consultation) with a healthcare professional specialised in behavioural change and/or motivational interviewing. When anxiety or depression is suspected, a psychologist should be consulted.

If telePEP treatment sessions focus mainly on behavioural change in PA, smoking, alcohol consumption, nutrition or stress, patients can be treated by a healthcare professional specialised in behavioural change and/or motivational interviewing under supervision of a psychologist. When the treatment sessions focus mainly on anxiety and/or depression, direct guidance by a psychologist should be warranted.

\section{Remote monitoring and coaching}

Monitoring of treatment progression and communication can be performed through an online application (secured messaging) and/or telephone and/or video consultation. The online application may include homework assignments, educational reading and questionnaires to monitor treatment progression. Remote coaching may be combined with face-to-face appointments. Mobile applications (e.g. mindfulness or food diary applications) or wearable devices (e.g. HR monitors or accelerometers) can be utilised to support the behavioural change programme.

\section{Implications for clinical practice}

To our knowledge, the addendum on CTR to the Dutch Multidisciplinary Guideline for Cardiac Rehabilitation [1] is the first CTR guideline worldwide. CTR is a promising alternative to centre-based CR for several reasons. First, it may overcome several barriers that currently limit patient participation in CR. Barriers frequently mentioned by patients are transport difficulties, costs, work or social obligations, or a preference for individual instead of group training. However, whether implementation of CTR actually leads to increased participation levels has yet to be evaluated. Second, implementation of CTR may reduce healthcare and/or socio-economic costs. CTR has proved to be at least as cost-effective as centre-based CR. The FIT@Home trial showed reduced absenteeism from work in patients following CTR compared to centre-based CR [29]. The Telerehab III trial showed reduced rehospitalisation rates in patients following CTR as an addition to centre-based CR, compared to centre-based CR alone [28]. Reductions in healthcare costs may serve as an important argument for widespread implementation of CTR, especially since limited training facilities and budget ceilings at CR centres prevent these centres from delivering centre-based CR to all eligible patients. Third, CTR has the potential to improve long-term cardio- vascular risk factor management, as self-monitoring of PA increases levels of self-management and selfcare, potentially improving lifestyle in the long term. Some recent studies reported higher PA levels in CTR participants after 6 months as compared with centrebased CR [44, 45], whereas another study reported similar PA levels after 1 year [29]. The 4 -year followup of the FIT@Home trial will provide insight into the long-term effectiveness of CTR.

\section{Future perspectives}

Although CTR has been shown to be a valid alternative to centre-based CR, near-future developments may increase its uptake and effectiveness, and improve patient satisfaction. Evidence suggests that after initial improvements in lifestyle behaviour following CR, patients often relapse into unhealthy behaviours [22, 46]. Currently, centre-based CR and CTR programmes consist of 12-week interventions, after which patients are followed-up by their cardiologist and/or general practitioner in (bi-)yearly visits. CTR lends itself well for prolonged (beyond 12 weeks) interventions, in which relapse into unhealthy lifestyle behaviours may be prevented by on-demand coaching, on the condition that such interventions are reimbursed by healthcare insurers. The results of extended centrebased CR programmes have so far been disappointing [47]; CTR may potentially be more effective due to better integration of CR into the daily life of participants, and the addition of self-monitoring of lifestyle behaviour. In addition, insights from the marketing domain on e-persuasion and personalisation strategies [48] may lead to further personalisation and tailoring of CTR interventions, making them usable for multiple subgroups that are relatively underrepresented in $\mathrm{C}(\mathrm{T}) \mathrm{R}$ (e.g. female and elderly patients, patients with low socio-economic status) [49]. Finally, CTR-like interventions may be implemented for cardiovascular prevention or in other chronic conditions (e.g. diabetes mellitus, cerebrovascular disease) where healthy lifestyle behaviour is essential.

\section{Conclusion}

Multidisciplinary or exercise-based CTR is a safe and cost-effective alternative to centre-based CR in patients with CAD or CHF. Implementation of CTR may lead to increased CR participation levels, improved long-term cardiovascular risk management and, ultimately, reduced healthcare and societal costs. Future adaptations of current CTR interventions will likely further increase their effectiveness and applicability in varied patient populations.

Acknowledgements We thank the members of the Landelijk Multidisciplinair Overleg Hartrevalidatie for their contribution to the creation of the addendum on CTR: I. van den Broek, J. van Dijk, B. Geleijnse, A.L. Gho-The, H. Koers, P. van Leeuwen, E. Los, T. Merkus, V. Niemeijer, J. Oudhof, J. Siebers, 
A. Snoek, K. Szabo-te Fruchte, A. Tewes, S. Traa, A. Venema, L. Visser, S. van der Voort.

Conflict of interest R.W.M. Brouwers, H.J. van Exel, J.M.C. van Hal, H.T. Jorstad, E.P. de Kluiver, R.A. Kraaijenhagen, P.M.J.C. Kuijpers, M.R. van der Linde, R.F. Spee, M. Sunamura, N.H.M.K. Uszko-Lencer, T. Vromen, M.E. Wittekoek and H.M.C. Kemps declare that they have no competing interests.

Open Access This article is licensed under a Creative Commons Attribution 4.0 International License, which permits use, sharing, adaptation, distribution and reproduction in any medium or format, as long as you give appropriate credit to the original author(s) and the source, provide a link to the Creative Commons licence, and indicate if changes were made. The images or other third party material in this article are included in the article's Creative Commons licence, unless indicated otherwise in a credit line to the material. If material is not included in the article's Creative Commons licence and your intended use is not permitted by statutory regulation or exceeds the permitted use, you will need to obtain permission directly from the copyright holder. To view a copy of this licence, visit http://creativecommons.org/licenses/by/4.0/.

\section{References}

1. Committee for Cardiovascular Prevention, Cardiac Rehabilitation of the Netherlands Society of Cardiology, Landelijk Multidisciplinair Overleg Hartrevalidatie. Addendum telerevalidatie in multidisciplinaire richtlijn hartrevalidatie. 2018. https://www.nvvc.nl/Kwaliteit/ Richtlijnen/Addendum\%20richtlijn\%20hartrevalidatie \%20-1-.pdf. Accessed 26 Feb 2020.

2. Anderson L, Thompson DR, Oldridge N, et al. Exercisebased cardiac rehabilitation for coronary heart disease. Cochrane Database Syst Rev. 2016; https://doi.org/10. 1002/14651858.CD001800.pub3.

3. Long L, Mordi IR, Bridges C, et al. Exercise-based cardiac rehabilitation for adults with heart failure. Cochrane Database Syst Rev. 2019;1:CD3331.

4. de Vries H, Kemps HM, van Engen-Verheul MM, et al. Cardiac rehabilitation and survival in a large representative community cohort of Dutch patients. Eur Heart J. 2015;36:1519-28.

5. Netherlands Society of Cardiology, Netherlands Heart Foundation. Multidisciplinary guidelines for cardiac rehabilitation. 2011. https://www.nvvc.nl/Richtlijnen/ Multidisciplinaire\%20Richtlijn\%20Hartrevalidatie\%202011 \%2023052011.pdf. Accessed 26 Feb 2020.

6. Committee for Cardiovascular Prevention, Cardiac Rehabilitation of the Netherlands Society of Cardiology, Landelijk Multidisciplinair Overleg Hartrevalidatie. Beslisboom Poliklinische Indicatiestelling Hartrevalidatie 2012. 2012. https://www.nvvc.nl/Richtlijnen/Beslisboom $\% 20$ Hartrevalidatie\%202012\%20-website-.pdf. Accessed 26 Feb 2020.

7. Kemps HMC, van Engen-Verheul MM, Kraaijenhagen RA, et al. Improving guideline adherence for cardiac rehabilitation in the Netherlands. Neth HeartJ.2011;19:285-9.

8. Knuuti J, Wijns W, Saraste A, et al. 2019 ESC Guidelines for the diagnosis and management of chronic coronary syndromes. Eur HeartJ. 2020;41(3):407-77.

9. Ibanez B, James S, Agewall S, et al. ESC Guidelines for the management of acute myocardial infarction in patients presenting with ST-segment elevation: the Task Force for the management of acute myocardial infarction in patients presenting with ST-segment elevation of the European Society. Eur Heart J. 2017;2018(39):119-77.

10. Roffi M, Patrono C, Collet JP, et al. 2015 ESC guidelines for the management of acute coronary syndromes in patients presenting without persistent ST-segment elevation: task force for the management of acute coronary syndromes in patients presenting without persistent ST-segment elevation of the European Society of Cardiology (ESC). Eur Heart J.2016;37:267-315.

11. Ades PA, Keteyian SJ, Wright JS, et al. Increasing cardiac rehabilitation participation from $20 \%$ to $70 \%$ : a road map from the Million Hearts Cardiac Rehabilitation Collaborative. Mayo Clin Proc. 2017;92:234-42.

12. Kotseva K, Wood D, De Bacquer D. Determinants of participation and risk factor control according to attendance in cardiac rehabilitation programmes in coronary patients in Europe: EUROASPIRE IV survey. Eur J Prev Cardiol. 2018;25:1242-51.

13. van Engen-Verheul M, de Vries H, Kemps H, et al. Cardiac rehabilitation uptake and its determinants in the Netherlands. Eur J Prev Cardiol. 2013;20:349-56.

14. Vries H de, Kemps HMC, Kraaijenhagen RA, etal. Deelname aan hartrevalidatieprogramma's in Nederland, 2007-2011. In: Koopman C, Van Dis I, Vaartjes I, et al., editors. Harten vaatziekten in Nederland 2014, cijfers over kwaliteit van leven, ziekte en sterfte. Den Haag: Hartstichting; 2014.

15. Clark AM, King-Shier KM, Duncan A, et al. Factors influencing referral to cardiac rehabilitation and secondary prevention programs: a systematic review. Eur J Prev Cardiol. 2013;20:692-700.

16. McDonall J, Botti M, Redley B, et al. Patient participation in a cardiac rehabilitation program. J Cardiopulm Rehabil Prev. 2013;33:185-8.

17. Wittmer M, Volpatti M, Piazzalonga S, et al. Expectation, satisfaction, and predictors of dropout in cardiac rehabilitation. Eur J Prev Cardiol. 2012;19:1082-8.

18. Sunamura M, ter Hoeve N, Geleijnse ML, et al. Cardiac rehabilitationin patients whounderwent primarypercutaneous coronary intervention for acute myocardial infarction: determinants of programme participation and completion. Neth Heart J. 2017;25:618-28.

19. Clark AM, King-Shier KM, Spaling MA, et al. Factors influencing participation in cardiac rehabilitation programmes after referral and initial attendance: qualitative systematic review and meta-synthesis. Clin Rehabil. 2013;27:948-59.

20. Kunal NK, Davies P, Taylor F, et al. Promoting patient uptake and adherence in cardiac rehabilitation. Cochrane Database Syst Rev. 2014;6:CD7131.

21. Kotseva K, Wood D, De Bacquer D, et al. EUROASPIRE IV: a European Society of Cardiology survey on the lifestyle, risk factor and therapeutic management of coronary patients from 24 European countries. Eur J Prev Cardiol. 2016;23:636-48.

22. Willich SN, Muller-Nordhorn J, Kulig M, et al. Cardiac riskfactors, medication, and recurrent clinical events after acute coronary disease; a prospective cohort study. Eur HeartJ. 2001;22:307-13.

23. Frederix I, Caiani EG, Dendale P, et al. ESC e-Cardiology Working Group position paper: overcoming challenges in digital health implementation in cardiovascular medicine. Eur J Prev Cardiol. 2019; https://doi.org/10. 1177/2047487319832394.

24. Frederix I, Vanhees L, Dendale P, et al. A review of telerehabilitation for cardiac patients. J Telemed Telecare. 2015;21:45-53. 
25. Rawstorn JC, Gant N, Direito A, et al. Telehealth exercisebased cardiac rehabilitation: a systematic review and metaanalysis. Heart. 2016;102:1183-92.

26. Huang K, Liu W, He D, et al. Telehealth interventions versus center-based cardiac rehabilitation of coronary artery disease: a systematic review and meta-analysis. Eur J Prev Cardiol. 2015;22:959-71.

27. van Veen E, Bovendeert JFM, Backx FJG, et al. E-coaching: new future for cardiac rehabilitation? A systematic review. PatientEduc Couns. 2017;100:2218-30.

28. Frederix I, Hansen D, Coninx K, et al. Effect of comprehensive cardiac telerehabilitation on one-year cardiovascular rehospitalization rate, medical costs and quality of life: a cost-effectiveness analysis. Eur J Prev Cardiol. 2016;23:674-82.

29. Kraal JJ, Van den Akker-Van Marle ME, Abu-Hanna A, et al. Clinicaland cost-effectiveness of home-based cardiacrehabilitation compared to conventional, centre-based cardiac rehabilitation: results of the FIT@Home study. Eur J Prev Cardiol. 2017;24:1260-73.

30. Piepoli MF, Hoes AW, Agewall S, et al. European guidelines on cardiovascular disease prevention in clinical practice. Eur Heart J. 2016;37:2315-81.

31. Anderson L, Sharp GA, Norton RJ, et al. Home-based versus centre-based cardiac rehabilitation. Cochrane Database Syst Rev. 2017;6:CD7130.

32. Piepoli MF, Corrà U, Dendale $\mathrm{P}$, et al. Challenges in secondary prevention after acute myocardial infarction: a call for action. Eur Heart J Acute Cardiovasc Care. 2017;6:299-310.

33. Committee for Cardiovascular Prevention, Cardiac Rehabilitation of the Netherlands Society of Cardiology, Landelijk Multidisciplinair Overleg Hartrevalidatie. NVVC Practice guidelines for cardiac rehabilitation. 2011. https://www.nvvc.nl/Richtlijnen/Geautoriseerde \%20NVVC\%20Praktijkrichtlijn\%20Hartrevalidatie \%20maart\%202011.pdf. Accessed 26 Feb 2020.

34. Beckers PJ, Denollet J, Possemiers NM, et al. Maintaining physical fitness of patients with chronic heart failure: a randomized controlled trial. Eur J Cardiovasc Prev Rehabil. 2010;17:660-7.

35. Ribeiro PAB, Boidin M, Juneau M, et al. High-intensity interval training in patients with coronary heart disease: prescription models and perspectives. Ann Phys Rehabil Med. 2017;60:50-7.

36. Aamot IL, Forbord SH, Gustad K, et al. Home-based versus hospital-based high-intensity interval training in cardiac rehabilitation: a randomized study. Eur J Prev Cardiol. 2014;21:1070-8.

37. Achttien RJ, Vromen T, Staal JB, et al. Development of evidence-based clinical algorithms for prescription of exercise-based cardiac rehabilitation. Neth Heart J. 2015;23:563-75.
38. Butte NF, Ekelund U, Westerterp KR. Assessing physical activity using wearable monitors: measures of physical activity. Med SciSports Exerc. 2012;44:5.

39. Westerterp KR. Reliable assessment of physical activity in disease: an update on activity monitors. Curr Opin Clin Nutr Metab Care. 2014;17:401-6.

40. Warren JM, Ekelund U, Besson H, et al. Assessment of physical activity - a review of methodologies with reference to epidemiological research: a report of the exercise physiology section of the European Association of Cardiovascular Prevention and Rehabilitation. Eur J Cardiovasc Prev Rehabil. 2010;17:127-39.

41. Janssen V, De Gucht V, Dusseldorp E, et al. Lifestyle modification programmes for patients with coronary heart disease: a systematic review and meta-analysis of randomized controlled trials. Eur J Prev Cardiol. 2013;20:620-40.

42. Reid RD, Morrin LI, Beaton LJ, et al. Randomized trial of an internet-based computer-tailored expert system for physical activity in patients with heart disease. Eur J Prev Cardiol. 2012;19(6):1357-64.

43. Riegel B, Moser DK, Buck HG, et al. Self-care for the prevention and management of cardiovascular disease and stroke: a scientific statement for healthcare professionals from the American Heart Association. J Am Heart Assoc. 2017;6(9):e6997. https://doi.org/10.1161/JAHA.117. 006997.

44. Frederix I, Hansen D, Coninx K, et al. Medium-term effectiveness of a comprehensive internet-based and patientspecific telerehabilitation program with text messaging support for cardiac patients: randomized controlled trial. J Med Internet Res. 2015; 17:e185.

45. Maddison R, Rawstorn JC, Stewart RAH, et al. Effects and costs of real-time cardiac telerehabilitation: randomised controlled non-inferiority trial. Heart. 2019;105:122-9.

46. Giannuzzi P, Temporelli PL, Marchioli R, et al. Global secondary prevention strategies to limit event recurrence after myocardial infarction: results of the GOSPEL study, a multicenter, randomized controlled trial from the Italian Cardiac Rehabilitation Network. Arch Intern Med. 2008;168:2194-204.

47. Sunamura M, ter Hoeve N, van den Berg-Emons RJG, et al. Randomised controlled trial of two advanced and extended cardiac rehabilitation programmes. Heart. 2018;104:430-7.

48. Kaptein M, Eckles D, Davis J. Envisioning persuasion profiles: challenges for public policy and ethical practice. Interactions. 2011;18:66-9.

49. Prescott E, Meindersma EP, van der Velde AE, et al. A European study on effectiveness and sustainability of current cardiac rehabilitation programmes in the elderly: design of the EU-CaRE randomised controlled trial. Eur J Prev Cardiol. 2016;23:27-40. 